\title{
Identification of Resistance to Multiple Fungicides in Field Populations of Venturia inaequalis
}

Kimberly S. Chapman, Department of Botany and Plant Pathology, Purdue University, West Lafayette, IN 47907; George W. Sundin, Department of Plant Pathology, 103 CIPS, Michigan State University, East Lansing 48824; and Janna L. Beckerman, Department of Botany and Plant Pathology, Purdue University, West Lafayette, IN 47907

\begin{abstract}
Chapman, K. S., Sundin, G. W., and Beckerman, J. L. 2011. Identification of resistance to multiple fungicides in field populations of Venturia inaequalis. Plant Dis. 95:921-926.

Venturia inaequalis, the causal agent of apple scab, is controlled primarily by fungicides. Long-term, extensive fungicide use has led to the development of resistance to multiple fungicides. To assess fungicide resistance, isolates of $V$. inaequalis were collected from Indiana and Michigan orchards. Single-spore derived isolates were evaluated by mycelium growth assays with previously determined discriminatory doses on media containing dodine, kresoxim-methyl, myclobutanil, or thiophanate-methyl. Of 195 isolates tested, 5.2, 0.7, 57.0, and 92.6\% of

clobutanil, and thiophanate-methyl, respectively. This is the first report of kresoxim-methyl field resistance in these states. Isolates resistant or shifted to a single fungicide were often found to have multiple fungicide resistance. Of all isolates tested, $38 \%$ were identified as resistant or shifted to two fungicides, and $12 \%$ were resistant or shifted to all four fungicides tested. No fitness penalty was found for isolates resistant to multiple fungicides based on a statistical analysis of mycelial growth and conidial production.
\end{abstract} isolates were found to be resistant to dodine, kresoxim-methyl, my-
The Midwest region of the United States produced an estimated 4.5 million metric tons of apples (Malus $\times$ domestica Borkh.) with a value of approximately $\$ 2.2$ billion in 2008 , making apples an economically important tree fruit crop in this region (28). Apple scab, caused by the fungus Venturia inaequalis (Cke) Wint., is one of the most destructive diseases of apples, infecting fruits, leaves, petioles, flowers, new shoots, and peduncles (23). Management of apple scab relies heavily upon fungicides and may require up to 12 fungicide applications in a single growing season (10). Many different fungicide modes of action have been used for the control of apple scab; in addition, those fungicides with curative properties provide an added level of protection because these fungicides inhibit growth after the initial infection of the pathogen (9).

The use of fungicides for control of apple scab, and the development of fungicide resistance in $V$. inaequalis, have a long history. Dodine (Syllit) was first released in 1959 to control scab, and 10 years later resistance was first recorded in New York (35). Concurrent with the development of dodine resistance, apple growers relied on the methyl benzimidazole carbamate (MBC) fungicides, such as benomyl (Benlate) and thiophanate-methyl (Topsin M). These systemic fungicides were used until resistance developed in the 1970s $(11,32)$. The development of resistance to both dodine and the MBC class of fungicides resulted in the discontinued use of these fungicides for apple scab management.

Today, growers rely on two classes of curative fungicides, the demethylation inhibitors (DMIs) and the quinone-outside inhibitors (QoI). Many DMI fungicides were introduced to control diseases of tree fruits in the 1980s (20). One of the most frequently used DMIs for apple scab is myclobutanil (Nova/Rally), which acts as a protectant and provides curative effects (19). However, after 10 years of testing at an experiment station in Nova Scotia, Canada, practical resistance of $V$. inaequalis to DMI fungicides was documented $(4,5)$. QoI fungicides, including strobilurin fungicides, are

Corresponding author: Janna L. Beckerman, E-mail: jbeckerm@ @urdue.edu

Accepted for publication 9 March 2011.

doi:10.1094/PDIS-12-10-0899

(C) 2011 The American Phytopathological Society systemic with varying degrees of mobility in plant tissue $(3,31)$, and have been labeled for management of apple scab in the United States since 1999 (37). Two common strobilurin fungicides widely used in apple production are kresoxim-methyl (Sovran) and trifloxystrobin (Flint). A study in 2004 by Köller et al. (15) showed that $V$. inaequalis isolates collected from a Michigan orchard had decreased sensitivity to this class of fungicides after only 2 years of strobilurin use.

During the past four decades, the release of fungicides with new modes of action has occurred concomitant with the development of resistance in older fungicide classes, which has reduced the impact of fungicide resistance in apple scab management. However, curative fungicides with new modes of action are not currently being developed. The presence of populations with reduced sensitivity to fungicides, classified as either shifted (progressing toward resistant) or resistant, creates challenges in controlling apple scab since use of the curative fungicides is limited due to decreasing efficacy and label restrictions.

The objective of this study was to test $V$. inaequalis isolates collected from Indiana and Michigan during the 2007 through 2009 growing seasons for the presence of fungicide resistance. The need for this study arose from grower concerns of decreased efficacy of DMI and strobilurin fungicides in controlling apple scab, and the lack of more recent information regarding the efficacy of dodine for apple scab management. The end result of this study included orchard-specific information for growers detailing the fungicide resistance in $V$. inaequalis populations, and phenotypic data regarding the efficacy of dodine in apple scab control and fungicide resistance management.

\section{Materials and Methods}

Fungal isolates. One hundred ninety-five single-spore isolates of $V$. inaequalis were collected from two locations in Indiana in 2007, one orchard in Indiana and seven orchards and one experimental orchard in Michigan during 2008, and one additional orchard in Indiana in 2009. These isolates were obtained from sites reporting suspected issues of fungicide resistance (Fig. 1). Sixtythree single-spore isolates from crabapple trees never treated with fungicides also were collected and used to confirm fungicide-sensitivity baselines (data not shown). Isolates were obtained by rubbing apple scab leaf lesions across the surface of $2 \%$ water agar 
(Bacto Agar, Difco) amended with $0.5 \mathrm{mg} / \mathrm{ml}$ ampicillin and 0.1 $\mathrm{mg} / \mathrm{ml}$ penicillin and streptomycin. After $24 \mathrm{~h}$, individual germinated conidia were removed with a sterile needle and placed on potato dextrose agar (PDA) (Difco) amended with $0.5 \mathrm{mg} / \mathrm{ml} \mathrm{am-}$ picillin and $0.1 \mathrm{mg} / \mathrm{ml}$ penicillin and streptomycin. Germinated spores were incubated in the dark at $22^{\circ} \mathrm{C}$ for 2 weeks or until enough growth was present to subculture to a fresh PDA plate.

Mycelial growth assays. Isolates were tested for sensitivity to dodine (technical grade, 99\% active ingredient [a.i.], Supelco, Park), kresoxim-methyl (commercial formulation, $50 \%$ a.i., Sovran, BASF Crop Protection), myclobutanil (commercial formulation, 40\% a.i., Rally 40WSP, Dow AgroSciences), and thiophanatemethyl (commercial formulation, $70 \%$ a.i., Topsin M 70WP, United Phosphorus Inc.) with conventional assays of mycelial growth (13). Salicylhydroxamic acid (SHAM, Sigma-Aldrich Inc.) was added with kresoxim-methyl to block the alternate respiration pathway (26). Fungicides were dissolved in water and then dispensed, along with $0.5 \mathrm{mg} / \mathrm{ml}$ ampicillin and $0.1 \mathrm{mg} / \mathrm{ml}$ penicillin and streptomycin, into autoclaved PDA. All control media were

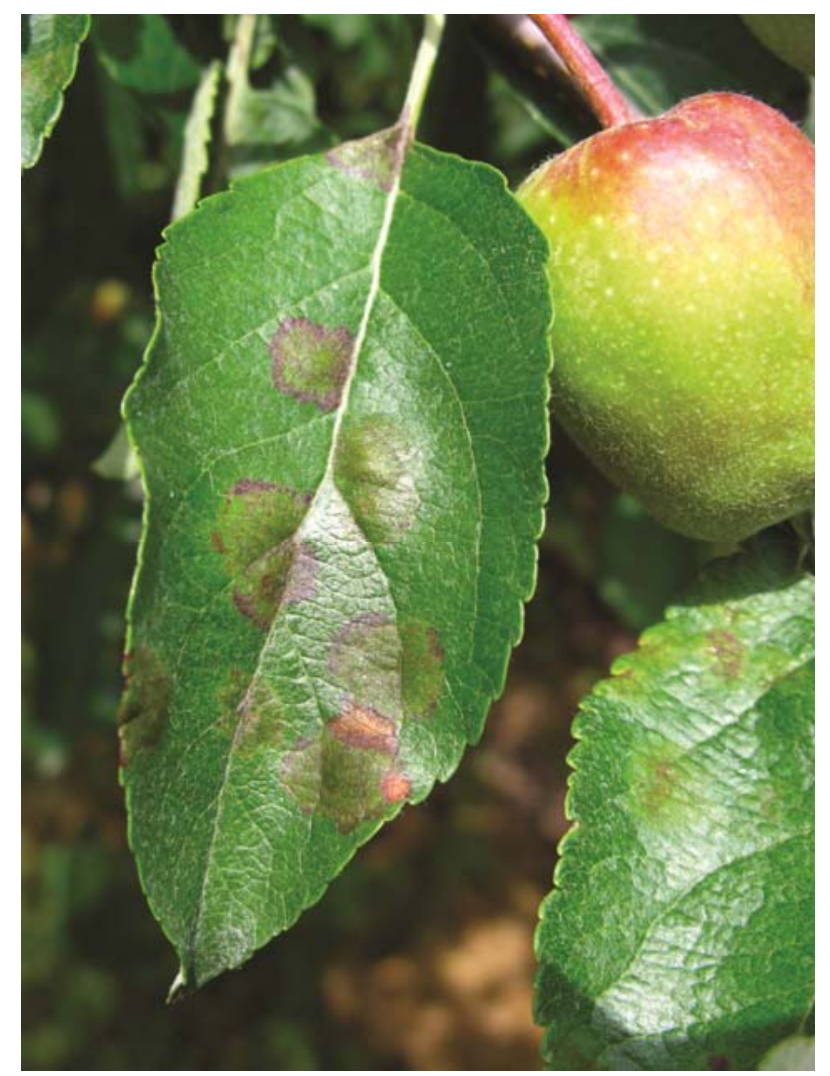

Fig. 1. Venturia inaequalis, causal fungus of apple scab, observed breaking through a fungicide application. Leaf discoloration can result when a fungicide effectively inhibits fungal growth. However, when $V$. inaequalis is tolerant to the fungicide, the fungus will resume growth, indicating that the fungal population may be resistant to the fungicidal mode of action. also amended with the antibiotics as above. Four-millimeter plugs of agar containing mycelium were placed on PDA or PDA amended with one of the fungicides. The concentrations of fungicides used are listed in Table 1. Three replicates of each isolate were used to test each fungicide and control. Three isolates were repeatedly tested and served as media controls. Plates were incubated at $19^{\circ} \mathrm{C}$ with a 12 -h light cycle under fluorescent lights for 30 days prior to assessment. Radial growth was determined by two perpendicular measurements of the colony diameter. The percent relative growth $(\mathrm{RG})$ was calculated by dividing the mean radial growth on the fungicide-amended medium by the mean radial growth on the nonamended medium, multiplied by 100 . A percent RG for each of the four fungicides was calculated for each isolate and compared to previously published thresholds (Table 1) in order to classify isolates as sensitive $(\mathrm{S})$, shifted $(\mathrm{SH})$, or resistant $(\mathrm{R})$ for each of the fungicides.

Assessment of fitness penalty. Forty-two isolates ranging from sensitive to shifted and/or resistant to analytical dodine, kresoximmethyl, myclobutanil, and thiophanate-methyl were selected to determine if a fitness penalty was associated with decreased sensitivity to any of the fungicides. The three replicated control plates from the growth assays described above were used to obtain radial growth measurements for the isolates in the same manner as in the mycelial growth assays. These plates were flooded with $1 \mathrm{ml}$ of sterile water and gently rubbed with a rubber policeman to dislodge the conidia. The conidia were collected in a sterile $1.5-\mathrm{ml}$ microcentrifuge tube, and conidial concentrations were determined with a hemacytometer. Three replicates of each isolate were used for the growth measurements and spore concentrations. Multiple $t$ tests were performed with SAS 9.2 (SAS Institute Inc.) to compare mycelial growth measurements and spore concentrations.

\section{Results}

Analysis of mycelial growth assays. Based on previously established thresholds and baselines, resistance to all four of the fungicides was detected in varying frequencies of the $V$. inaequalis isolates examined in this study. Resistance to myclobutanil was present in more than $55 \%$ of the population, and approximately $40 \%$ of isolates were shifted to this fungicide. Only $7.7 \%$ of isolates were sensitive to myclobutanil, and the percent RG values ranged from 0 to $239 \%$. One percent of isolates tested were resistant to kresoxim-methyl and over $25 \%$ were classified as shifted; however, a majority of the population $(71.6 \%)$ was sensitive to the fungicide. The percent RG for isolates tested with kresoximmethyl ranged from 0 to $170 \%$. More than $80 \%$ of isolates were resistant to thiophanate-methyl, with $\mathrm{RG}$ values that ranged from 0 to $270 \%$. Approximately $8 \%$ of isolates were resistant to dodine and $32 \%$ of isolates were shifted, yet the greatest percentage of the population $(60 \%)$ was sensitive. The percent RG range was 0 to $126 \%$ for isolates tested with dodine (Fig. 2).

Variation within an orchard. Of 50 isolates from one orchard, 23 were sensitive to kresoxim-methyl, 26 were classified as shifted, and only one was resistant to the fungicide. No variation was detected among isolates tested with thiophanate-methyl, as all isolates were resistant. When isolates were tested with dodine, 26 isolates were sensitive, 20 were shifted, and three were resistant.

Table 1. Concentrations of fungicides added to potato dextrose agar media in parts per million and parameters for classification of isolates based on percent relative growth

\begin{tabular}{|c|c|c|c|c|}
\hline \multirow[b]{2}{*}{ Fungicide } & \multirow{2}{*}{$\begin{array}{l}\text { Concentration of fungicide } \\
\text { added to media }(\mu \mathrm{g} / \mathrm{ml})\end{array}$} & \multicolumn{3}{|c|}{ Classification relative growth parameters } \\
\hline & & Sensitive (S) & Shifted (SH) & Resistant (R) \\
\hline Kresoxim-methyl & $0.35\left(25^{\mathrm{a}}\right)$ & $\leq 39 \%$ & $40-90 \%(33)$ & $>90 \%(25)$ \\
\hline Salicylhydroxamic acid (SHAM) ${ }^{\mathrm{b}}$ & $100(26)$ & & & \\
\hline Thiophanate-methyl & $0.5(12)$ & $=0 \%$ & $\mathrm{n} / \mathrm{a}$ & $>0 \%(12)$ \\
\hline Analytical dodine & $0.2(18)$ & $\leq 50 \%$ & $51-90 \%$ & $>90 \%(16)$ \\
\hline Myclobutanil & $0.1(14)$ & $\leq 30 \%$ & $31-69 \%$ & $\geq 70 \%$ (34) \\
\hline
\end{tabular}

\footnotetext{
a Numbers listed in parentheses correspond to literature cited.

b SHAM is used to block the alternative respiration pathway.
} 
With myclobutanil, less variation was detected and isolates were classified as either shifted ( 9 isolates) or resistant (41 isolates).

Variation between orchards. All isolates collected from a Lafayette, IN, orchard and from the Meigs Farm at ThrockmortonPurdue Agricultural Center, IN, were sensitive to kresoxim-methyl (Fig. 3A and B). However, in an orchard in Hobart, IN, $2.0 \%$ of the isolates were found to be resistant to kresoxim-methyl and more than $50 \%$ shifted (Fig. 3C). The entire populations from the Lafayette and Hobart orchards and a majority, $88.9 \%$, at the Meigs site were resistant to thiophanate-methyl. The number of isolates resistant to dodine was $6.0 \%$ or less of the population in each orchard. However, isolates that were shifted comprised $40 \%$ of the populations in the Lafayette and Hobart sites, while only $28.3 \%$ of isolates were classified as shifted to dodine at the Meigs site. Resistance to myclobutanil was present in over $80 \%$ of the isolates from the Meigs and Hobart, IN, locations, and the remaining isolates were classified as shifted. No isolates from either location were sensitive to myclobutanil. At the Lafayette location, only $8.7 \%$ of isolates were resistant to myclobutanil and $65.2 \%$ were shifted for this fungicide. Differences in the number of isolates sensitive, shifted, or resistant to a fungicide as well as the types of fungicide resistance were also found among Michigan orchards (data not shown).

Variation between states. Resistance to all four of the fungicides tested was detected in isolates from Indiana and Michigan (Fig. 4A and B). In both states, kresoxim-methyl resistant isolates comprised a small percentage (less than $2 \%$ ) of the population. A total of $19.3 \%$ of isolates were shifted to kresoxim-methyl in Indiana, compared to $44.1 \%$ of isolates in Michigan that were identified as shifted. Resistance to thiophanate-methyl was present in 92.6 and $63.3 \%$ of the isolates from Indiana and Michigan, respectively. Dodine resistance was present in $5.2 \%$ of isolates from Indiana, while $34.1 \%$ of isolates were shifted. In Michigan, $13.3 \%$ of isolates were resistant to dodine and $28.3 \%$ were shifted. Isolates resistant to myclobutanil comprised $55 \%$ or more of the populations in both states. In Indiana, $34.1 \%$ of isolates were shifted and in Michigan, $40.0 \%$ were shifted to myclobutanil.

Assessment of multiple resistances. All isolates from Indiana and Michigan were assessed for resistance to multiple fungicides (Fig. 5). One percent of all isolates were sensitive to all four of the

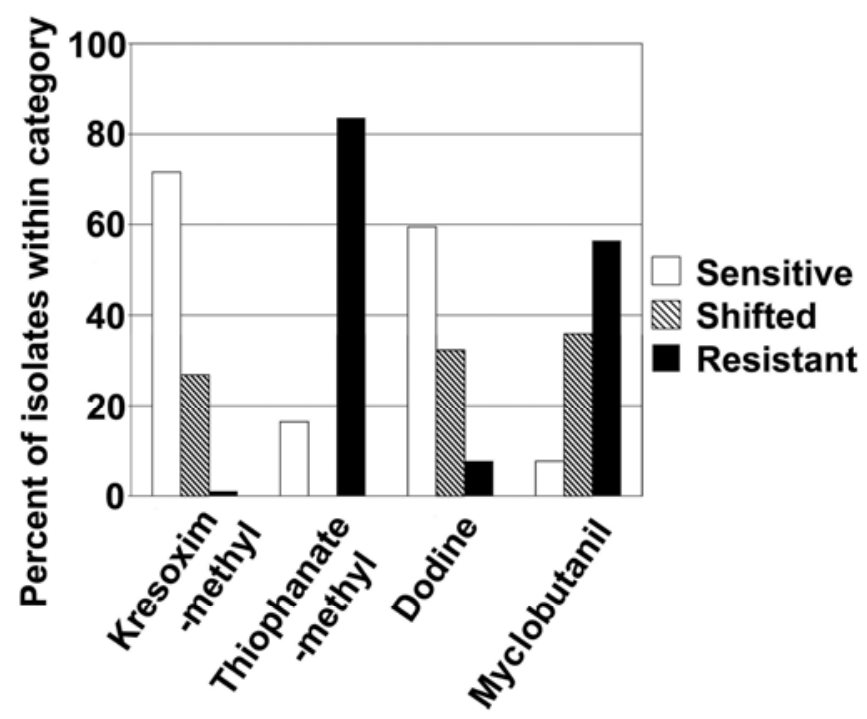

Fungicide active ingredient

Fig. 2. Percentage of all Venturia inaequalis isolates collected from Indiana and Michigan orchards that are classified as sensitive, shifted, or resistant. One hundred ninety-five isolates were tested for resistance with mycelial growth assay to the following fungicides at the corresponding discriminatory doses: thiophanatemethyl $(0.5 \mu \mathrm{g} / \mathrm{ml})$, dodine $(0.2 \mu \mathrm{g} / \mathrm{ml})$, myclobutanil $(0.1 \mu \mathrm{g} / \mathrm{ml})$, and kresoximmethyl $(0.35 \mu \mathrm{g} / \mathrm{ml})$. Resistance was present for all fungicides tested.

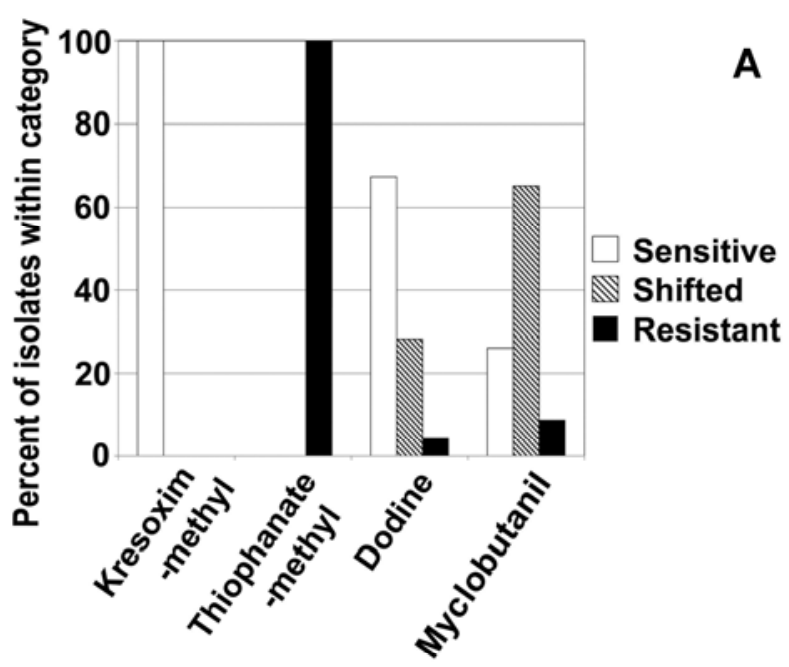

Fungicide active Ingredient
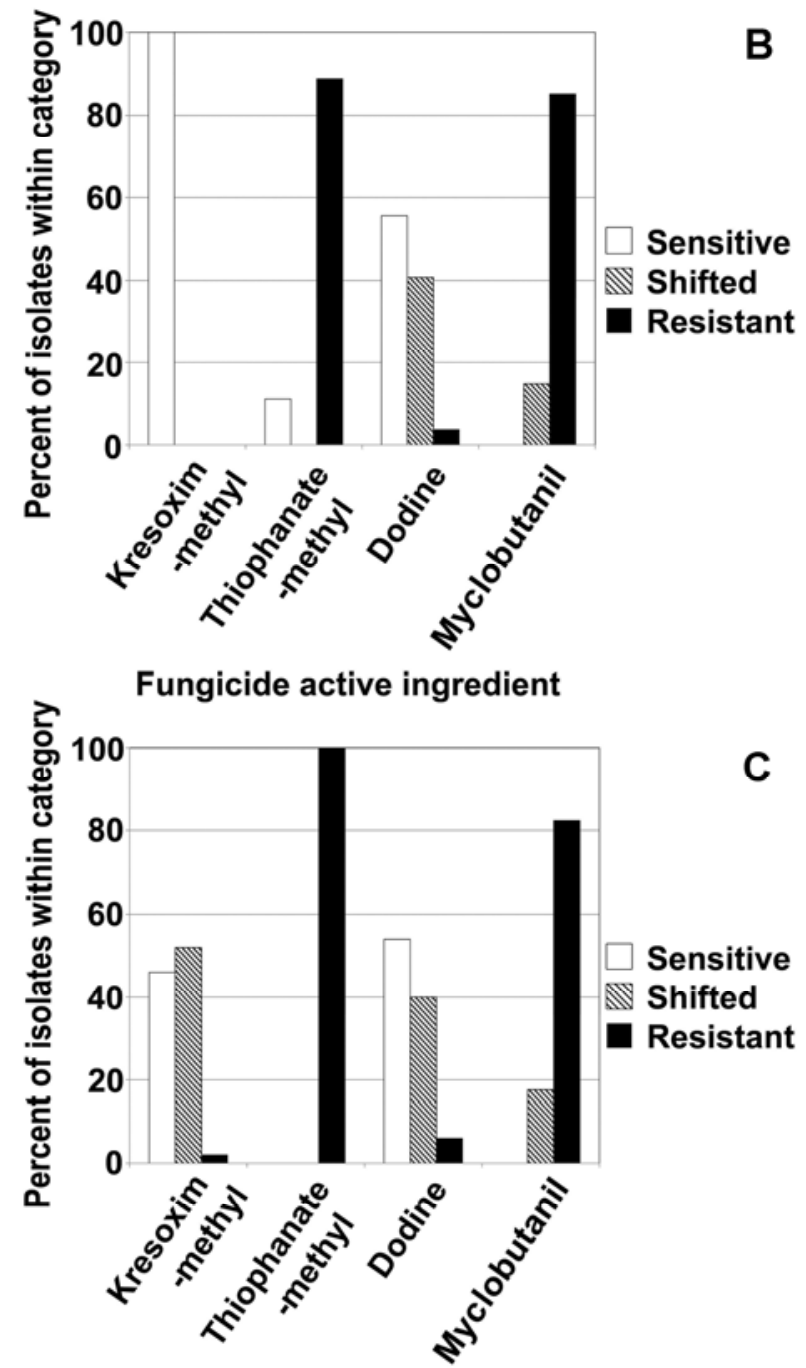

Fungicide active ingredient

Fig. 3. Percentage of Venturia inaequalis isolates collected and tested with mycelial growth assays for resistance to fungicides that were classified as sensitive, shifted, or resistant. The following fungicides were tested at the corresponding discriminatory doses: thiophanate-methyl $(0.5 \mu \mathrm{g} / \mathrm{ml})$, dodine $(0.2 \mu \mathrm{g} / \mathrm{ml})$, myclobutanil $(0.1$ $\mu \mathrm{g} / \mathrm{ml})$, and kresoxim-methyl $(0.35 \mu \mathrm{g} / \mathrm{ml})$. Isolates were collected: A, 44 from an orchard in Lafayette, IN, B, 27 from the Meigs Research Farm in ThrockmortonPurdue Agricultural Center, IN, and C, 50 from an orchard in Hobart, IN. The number of fungal isolates resistant, as well as the presence of resistance to each of the fungicides, differed between locations. 
fungicides tested, and $13 \%$ were resistant or shifted to only one of the fungicides. The largest proportion of the isolates (38\%) was resistant or shifted toward resistance to two of the fungicides and $35 \%$ of the isolates were resistant or shifted to three fungicides. The remaining $12 \%$ of the isolates were resistant or shifted to all four of the fungicides tested.

In Indiana, no isolates were found to be sensitive to all four fungicides, but $3 \%$ of the isolates from Michigan were found to be sensitive to all four of the fungicides. Most isolates were found to be resistant or shifted to two of the fungicides, with 40 and $35 \%$ of the population being classified this way for Indiana and Michigan, respectively. Isolates resistant or shifted to all four of the fungicides were found in $10 \%$ of isolates in Indiana and $17 \%$ of isolates in Michigan. In both states, when isolates were resistant or shifted to one fungicide, that fungicide most commonly was myclobutanil, and if resistant or shifted to two fungicides, these fungicides were myclobutanil and thiophanate-methyl. Among the Indiana isolates

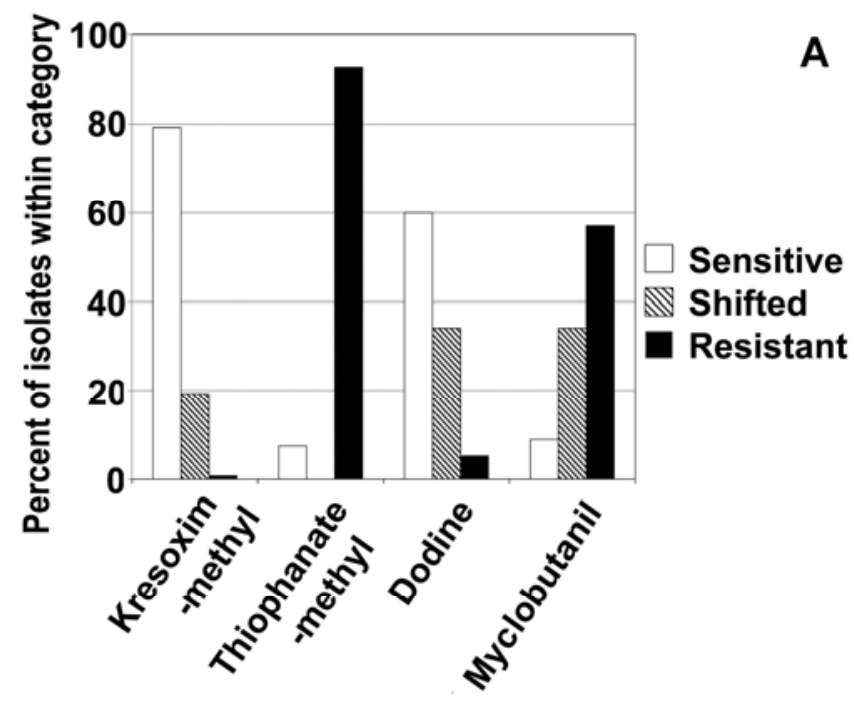

Fungicide active ingredient

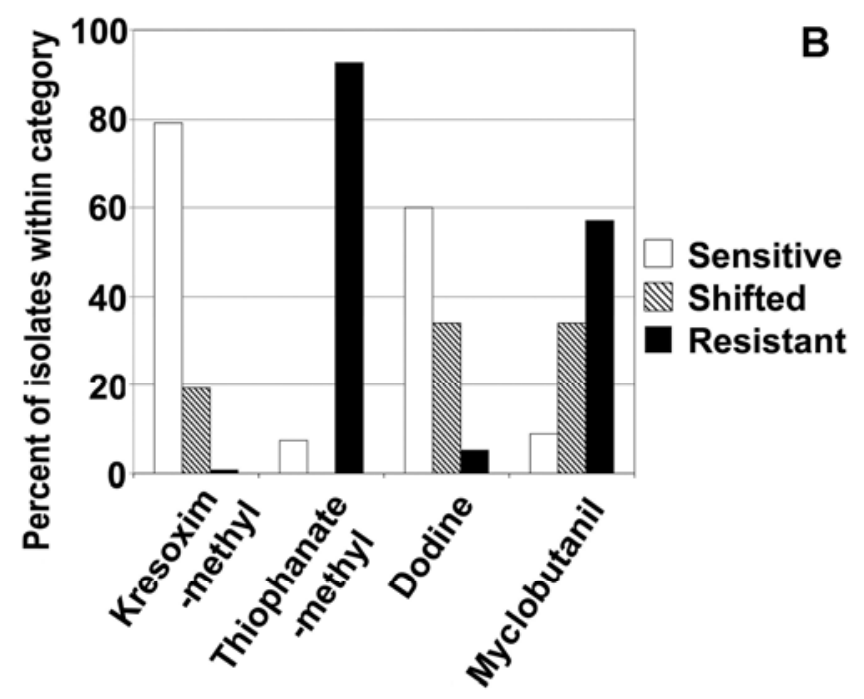

\section{Fungicide active ingredient}

Fig. 4. A, Percentage of Venturia inaequalis isolates collected and tested with mycelial growth assays for resistance to fungicides that were classified as sensitive, shifted, or resistant. The following fungicides were tested at the corresponding discriminatory doses: thiophanate-methyl $(0.5 \mu \mathrm{g} / \mathrm{ml})$, dodine $(0.2 \mu \mathrm{g} / \mathrm{ml})$, myclobutanil $(0.1 \mu \mathrm{g} / \mathrm{ml})$, and kresoxim-methyl $(0.35 \mu \mathrm{g} / \mathrm{ml})$. Isolates were collected: A, 135 from Indiana orchards, and B, 60 from Michigan orchards. Resistance was present for all fungicides tested in both Indiana and Michigan orchards. that were resistant or shifted to three fungicides, those fungicides were myclobutanil, thiophanate-methyl, and dodine, but in Michigan, the fungicides were myclobutanil, thiophanate-methyl, and kresoxim-methyl. Isolates from Indiana that were resistant or shifted to all four fungicides were most commonly shifted to kresoxim-methyl and dodine and resistant to thiophanate-methyl and myclobutanil; however, isolates from Michigan were shifted to kresoxim-methyl and resistant to thiophanate-methyl, dodine, and myclobutanil.

Assessment of fitness penalty. The mean values for growth and the conidial production by sensitive isolates were compared to isolates that were resistant to a single fungicide as well as to multiple fungicides, and no statistical significance was found. Since each $t$ test was performed independently, $P$ values varied, but the average $P$ value was 0.5 . No negative effect on growth or asexual reproduction was detected for isolates with single or multiple fungicide resistance.

\section{Discussion}

The results of this study document the occurrence of $V$. inaequalis isolates with reduced sensitivity to one or more of the four major curative fungicide classes used to manage apple scab. We subsequently found no evidence of a fitness penalty associated with single or multiple resistance phenotypes in in vitro studies. Previous studies have assessed fungicide resistance in $V$. inaequalis to dodine (18), kresoxim-methyl $(25,26)$, myclobutanil $(14,17)$, and thiophanate-methyl $(12,36)$ independently. This study tested these four fungicides on a population of $V$. inaequalis isolates simultaneously, which allowed for an assessment of multiple fungicide resistances. Our results revealed the widespread development of multiple fungicide resistances in the Midwest, and the first identification of strobilurin (kresoxim-methyl) resistance in Indiana and Michigan. With the greatest proportion of the isolates from both states resistant or shifted to two of the fungicides, management of apple scab and selection of strategies for preserving activity of the remaining effective fungicides becomes more complex. If isolates are resistant to multiple chemicals, techniques such as mixing fungicides with different modes of action or chemical rotations may not be effective disease management strategies. Some isolates were resistant or shifted to all four of the fungicides tested. Thus, if resistance is present in a large portion of the population, it is possible that none of the major curative fungicides labeled for apple scab will provide adequate disease control.
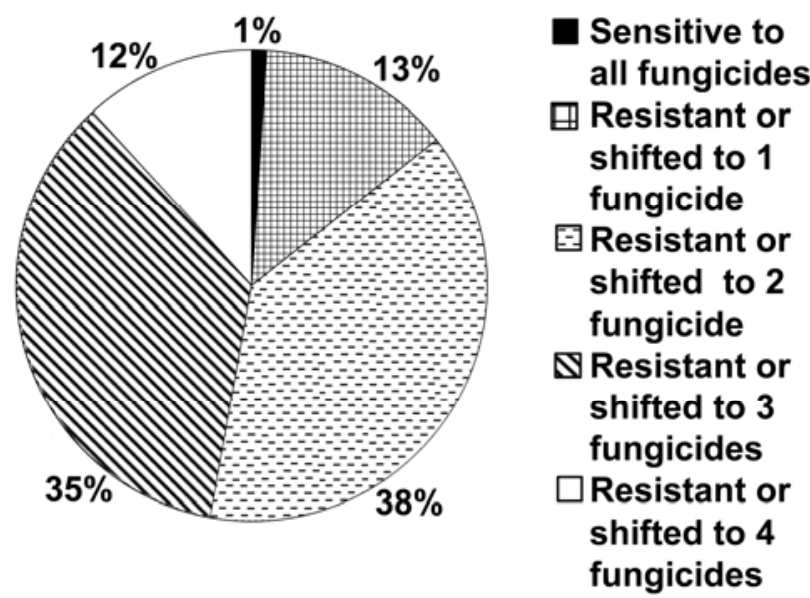

Fig. 5. Percentage of Venturia inaequalis isolates classified as resistant or shifted to one or more fungicides. One hundred ninety-five isolates were tested for resistance to the following fungicides at the corresponding discriminatory doses: thiophanate-methyl $(0.5 \mu \mathrm{g} / \mathrm{ml})$, dodine $(0.2 \mu \mathrm{g} / \mathrm{ml})$, myclobutanil $(0.1 \mu \mathrm{g} / \mathrm{ml})$, and kresoxim-methyl $(0.35 \mu \mathrm{g} / \mathrm{ml})$ with mycelial growth assays to determine the presence of multiple fungicide resistance. The greatest proportion of isolates was resistant or shifted to two of the fungicides, while the smallest percentage was sensitive to all of the fungicides. 
DMI fungicides were first labeled for use on tree fruits in the 1980s; however, resistance to the DMI class of fungicides is well established in $V$. inaequalis populations worldwide (20). The first report of resistance to myclobutanil was reported in Michigan in 1991 (17). Curiously, the first confirmed failure of myclobutanil was observed by the authors in an Indiana orchard in 2009. This time lag between the developments of myclobutanil resistance in these two states may be attributed to variations in management practices, differences in the timing of the initial use of the fungicide to manage apple scab, or a lack of fungicide resistance monitoring in Indiana prior to this study. Indiana growers produce apples primarily for the retail or direct market; in Michigan, over half the apples are sold to processors for juice, sauce, cider, or pie filling. These two markets have differing tolerances to blemishes such as scab, and because of reduced economic returns, a need to choose less costly fungicide programs.

Dodine was first used to manage apple scab in the late 1950s, but when resistance developed 10 years later, widespread use of the fungicide was discontinued (35). Further testing of resistant isolates of $V$. inaequalis by Köller et al. (18) showed that the frequency of resistance was reduced in the absence of dodine compared to continued use of dodine. However, when these orchards resumed use of dodine, resistance levels increased rapidly (18). Results of a study by Carisse and Jobin contradict those previous findings by detecting the presence of dodine resistance 30 years after discontinued use of the fungicide in orchards (7). Results of the present study showed that the number of isolates resistant to dodine comprised only a small percentage of the total population. Thus, recommendations have been made by extension specialists to use dodine only in orchards with low levels of resistance. However, if resistance can persist over time, reintroducing dodine into an orchard may increase selection pressure in the V. inaequalis population with reduced sensitivity to dodine. Therefore, dodine may provide adequate control of apple scab only for a short period of time, as the population would be expected to become resistant rapidly.

The use of thiophanate-methyl began in the 1970s, and resistance was reported a short time later in Australia in 1974 (36) and in Michigan in 1976 (11). Results of a later study of Botrytis cinerea in vineyards by Leroux and Clerjeau (21) showed that, in the absence of MBC fungicides, the MBC-resistant pathogen population persists and maintains their fitness. Due to the presence of populations of $V$. inaequalis resistant to thiophanate-methyl, this fungicide is no longer used for management of apple scab in commercial orchards. However, thiophanate-methyl is still applied for the management of other apple diseases such as sooty blotch and flyspeck. Hence, selection pressure may maintain high levels of thiophanate-methyl-resistant $V$. inaequalis populations.

Strobilurin fungicides were first used to manage apple scab in 1997, and resistance was reported in 2004 (15,27). Results of this study revealed only a small number of strobilurin-resistant isolates in the population. However, a high percentage of isolates in Indiana and Michigan are shifted, and the continued use of the strobilurin fungicides may cause these populations to progress further toward becoming resistant. Cross-resistance is common within the QoI class of fungicides (6). Consequently, once resistance to a strobilurin fungicide is established in the population, adequate levels of apple scab control may be unlikely with any strobilurin fungicide (6). When discussing fungicide resistance to the QoI class, it is important to consider the methods used for evaluating fungicide resistance. In the findings of Lesniak et al. (22), a PCRbased assay detected the G143A mutation in the CYTB gene that is associated with QoI-resistance in a majority of Michigan strains tested. The mycelial growth assays described herein evaluated the ability of these fungal isolates to grow, as well as a reduction in growth (shifting) or failure to grow on fungicide-amended media. The present assay detected a high degree of shifting in isolates, but very little absolute resistance. One potential reason for this inconsistency is the difference in biology between a newly germinated spore versus established mycelia (27), and the ratio between the mitochondria possessing the fungicide-resistant allele compared to the wild-type allele. The Lesniak et al. (22) paper detects the presence of the mutation; however, it is unknown if multiple copies of the resistant allele are present in a particular strain, or if they exist in a mixed population of mitochondria (heteroplasmy). Thus, the percentage of resistant mitochondria would control the phenotype observed in our mycelia growth assay, whereas the presence of the resistant allele is detected in the PCR assay.

Although the populations tested in this study of $V$. inaequalis of Indiana and Michigan show varying levels of fungicide sensitivity, these results do not provide an adequate basis for developing fungicide recommendations for an orchard. Instead, the profile of resistance for each orchard should be used to determine the fungicides that will provide the most effective control of apple scab. Sensitivity to fungicides within a pathogen population in an orchard can result from past fungicide practices and can also be influenced by surrounding orchards. Differences in fungicide resistance between orchards can be observed between the Lafayette, IN, orchard and the Meigs research farm, which are approximately $3 \mathrm{~km}$ apart. The entire sampled population of the Lafayette orchard was completely resistant to thiophanate-methyl, which is the result of a sole dependence on this fungicide for control of $V$. inaequalis. The majority of the Lafayette orchard population was classified as shifted or resistant to myclobutanil; however, this fungicide was not used at the Lafayette location until 2007, the same year isolates were collected. Therefore, applications of myclobutanil were not likely the cause for the population becoming less sensitive to myclobutanil, but may be a factor causing a high level of resistance at the Meigs site. If inoculum from the Meigs farm could reach the Lafayette site, a resistant population may have become established. Since ascospores are capable of traveling between 2 and $5 \mathrm{~km}$ from an inoculum source, this lends credibility to the movement of inoculum as a plausible explanation (1). A second potential explanation is the possibility that apple scab-susceptible hosts are growing at a location between the two sites and thus function as an inoculum reservoir. Such a reservoir would provide a location for the fungus to complete its sexual stage and produce ascospores with some level of resistance to myclobutanil. Dodine-resistant and shifted isolates were present in the population of $V$. inaequalis from the Meigs site even though this fungicide has never been used there. Regardless of the past practices or the influence from other orchards, the levels of fungicide resistance in an orchard influence the use of specific fungicides and the level of efficacy a grower can expect.

Fungicide resistance is a genetically inherited trait that may impose a fitness penalty, or negative effect on fungal growth, reproduction, or pathogenicity (6). Thus, multiple resistances would be expected to impose a greater penalty. Results of a study by Markoglou et al. (24) on Botrytis cinerea documented a fitness penalty associated with resistance to pyraclostrobin. However, studies of other plant pathogens have shown that little to no fitness penalty is associated with fungicide resistance $(2,8,13,30)$. We determined that there was no statistical evidence to support the conclusion that isolates resistant or shifted to one or more of the fungicides suffered a fitness penalty when compared to sensitive isolates, based on the parameters of mycelial growth and conidia production. This study shows that fungicide-resistant or shifted isolates are as fit as sensitive isolates and are, thus, equally capable of surviving and persisting in an orchard.

This study used mycelial growth assays to determine resistance and isolate shifts to four fungicides used in commercial apple orchards for management of apple scab. Mycelial growth assays are very labor-intensive and time-consuming for recalcitrant fungi such as $V$. inaequalis. While molecular techniques detect fungicide resistance more quickly, usually within hours or days, accuracy of the results may be lower (29). Molecular methods identify only the known resistant genotype of the fungus and not the phenotype, and thus can under- or over-report resistance (29). Mycelial growth assays identify the phenotype of the isolate and allow for easier detection of shifted isolates; thus, results are more accurate for 
fungicides with qualitative resistance, or those fungicides that affect growth after germination (i.e., the DMI class).

$V$. inaequalis isolates with reduced sensitivity to one or more of the four major curative fungicide classes used to manage apple scab were found in this study. Thus, growers face challenges in managing this disease. Historically, the introduction of fungicides with new modes of action has coincided with the development of resistance in an older fungicide class, reducing the impact of fungicide resistance in apple scab management. However, no curative fungicides with different modes of action have been introduced for apple scab control since the late 1990s. With resistant and shifted populations in both Indiana and Michigan, growers are faced with losing all of the curative fungicides used for apple scab management. Loss of these chemicals results in extreme challenges to growers to maintain adequate control of apple scab. Growers who continue to use these fungicides frequently in the presence of highly shifted and resistant populations of $V$. inaequalis in their orchards risk complete management failures and crop losses.

\section{Acknowledgments}

We thank Judy Santini for her statistical assistance, and Kiersten Wise and Larry Dunkle for editorial and scientific comments on the manuscript. We thank Adam Leonberger for his photographic assistance and image preparation. We also thank Maxwell McLennan and Kacie Quello for their assistance with the growth assays, and Kayla Gerberich for her help in obtaining new fungal isolates. This work was supported by startup funds from Purdue University, the Michigan Agricultural Experiment Station, and USDA-NIFA-NCIPM grant \#104637.

\section{Literature Cited}

1. Aylor, D. E. 1998. The aerobiology of apple scab. Plant Dis. 82:838-849.

2. Bardas, G. A., Myresiotis, C. K., and Karaoglanidis, G. S. 2008. Stability and fitness of anilinopyrimidine-resistant strains of Botrytis cinerea. Phytopathology 98:443-450.

3. Bartlett, D. W., Clough, J. M., Godwin, J. R., Hall, A. A., Hamer, M., and Parr-Dobrzanski, B. 2002. The strobilurin fungicides. Pest Manag. Sci. 58:649-662.

4. Braun, P. G. 1994. Development and decline of a population of Venturia inaequalis resistant to sterol-inhibiting fungicides. Norw. J. Agric. Sci. 17(Suppl.):173-184.

5. Braun, P. G., and McRae, K. B. 1992. Composition of a population of Venturia inaequalis resistant to myclobutanil. Can. J. Plant Pathol. 14:215-220.

6. Brent, K., and Hollomon, D. 2007. Fungicide Resistance: The Assessment of Risk. FRAC monogr. No. 2 (revised) edition. http://www.frac.info/ frac/publication/anhang/FRAC_Mono2_2007.pdf.

7. Carisse, O., and Jobin, T. 2010. Resistance to dodine in populations of Venturia inaequalis in Quebec, Canada. Online. Plant Health Progress doi:10.1094/PHP-2010-0614-01-RS.

8. Chin, K. M., Chavaillaz, D., Kaesbohrer, M., Staub, T., and Felsenstein, F. G. 2001. Characterizing resistance risk of Erysiphe graminis f. sp. tritici to strobilurins. Crop Prot. 20:87-96.

9. Hewitt, H. G. 1998. Fungicides in Crop Protection. CAB International, New York.

10. Jones, A. L., and Aldwinckle, H. S. 1991. Compendium of Apple and Pear Diseases. American Phytopathological Society, St. Paul, MN.

11. Jones, A. L., and Walker, R. J. 1976. Tolerance of Venturia inaequalis to dodine and benzimidazole fungicides in Michigan. Plant Dis. Rep. 60:4044.

12. Katan, T., Shabi, E., and Gilpatrick, J. D. 1983. Genetics of resistance to benomyl in Venturia inaequalis isolates from Israel and New York. Phytopathology 73:600-603.

13. Koenraadt, H., Somerville, S. C., and Jones, A. L. 1992. Characterization of mutations in the beta-tubulin gene of benomyl-resistant field strains of Venturia inaequalis and other plant pathogenic fungi. Phytopathology 82:13481354.
14. Köller, W., Parker, D. M., and Reynolds, K. L. 1991. Baseline sensitivities of Venturia inaequalis to sterol demethylation inhibitors. Plant Dis. 75:726728.

15. Köller, W., Parker, D. M., Turechek, W. W., Avila-Adame, C., and Cronshaw, K. 2004. A two-phase resistance response of Venturia inaequalis populations to the QoI fungicides kresoxim-methyl and trifloxystrobin. Plant Dis. 88:537-544.

16. Köller, W., and Wilcox, W. F. 2001. Evidence for the predisposition of fungicide-resistant phenotypes of Venturia inaequalis to a preferential selection for resistance to other fungicides. Phytopathology 91:776-781.

17. Köller, W., Wilcox, W. F., Barnard, J., Jones, A. L., and Braun, P. G. 1997. Detection and quantification of resistance of Venturia inaequalis populations to sterol demethylation inhibitors. Phytopathology 87:184-190.

18. Köller, W., Wilcox, W. F., and Jones, A. L., 1999. Quantification, persistence, and status of dodine resistance in New York and Michigan orchard populations of Venturia inaequalis. Plant Dis. 83:66-70.

19. Kuck, K. H., and Sheinpflug, H. 1986. Biology of sterol-biosynthesis inhibiting fungicides. In: Chemistry of Plant Protection. R. Wegler, ed. Springer-Verlag, Berlin.

20. Kuck, K. H., Scheinpflug, H., and Pontzen, R. 1995. DMI fungicides. Pages 205-258 in: Modern Selective Fungicides, 2nd ed. H. Lyr, ed. Gustav Fischer Verlag, Jena, Germany.

21. Leroux, P., and Clerjeau, M. 1985. Resistance of Botrytis cinerea Pers. and Plasmopara viticola (Berk. \& Curt.) Berl. and de Toni to fungicides in French vineyards. Crop Prot. 4:137-160.

22. Lesniak, K. E., Proffer, T. J., Beckerman, J. L., and Sundin, G. W. Occurrence of QoI resistance and detection of the G143A mutation in Michigan populations of Venturia inaequalis. Plant Dis. 95:927-934.

23. MacHardy, W. 1996. Apple Scab: Biology, Epidemiology, and Management. American Phytopathological Society, St. Paul, MN.

24. Markoglou, A. N., Malandrakis, A. A., Vitoratos, A. G., and Ziogas, B. N. 2006. Characterization of laboratory mutants of Botrytis cinerea resistant to QoI fungicides. Eur. J. Plant Pathol. 115:149-162.

25. Olaya, G., and Köller, W. 1999. Baseline sensitivities of Venturia inaequalis populations to the strobilurin fungicide kresoxim-methyl. Plant Dis. 83:274278.

26. Olaya, G., and Köller, W. 1999. Diversity of kresoxim-methyl sensitivities in baseline populations of Venturia inaequalis. Pestic. Sci. 55:1083-1088.

27. Olaya, G., Zheng, D., and Köller, W. 1998. Differential response of germinating Venturia inaequalis conidia to kresoxim-methyl. Pestic. Sci. 54:230236.

28. Perez, A., and Pollack, S. USDA-ERS. 2009. Fruit and Tree Nuts Outlook: FTS-339. Washington, D.C.: USDA Economic Research Service. http:// www.ers.usda.gov/publications/fts/2009/Sep/FTS339.pdf. Access date: 10 June 2010.

29. Quello, K., Chapman, K. S., and Beckerman, J. L. 2010. In situ detection of benzimidazole resistance in field populations of Venturia inaequalis in Indiana. Plant Dis. 94:744-750.

30. Raposo, R., Delcan, J., Gomez, V., and Melgarejo, P. 1996. Distribution and fitness of isolates of Botrytis cinerea with multiple fungicide resistance in Spanish greenhouses. Plant Pathol. 45:497-505.

31. Reuveni, M. 2001. Activity of trifloxystrobin against powdery and downy mildew disease of grapevines. Can. J. Plant Pathol. 23:52-59.

32. Russell, P. E. 1995. Fungicide resistance: Occurrence and management. J. Agric. Sci. 124:317-323.

33. Russell, P. E. 2004. Sensitivity baselines in fungicide resistance research and management. FRAC. http://www.frac.info/frac/publication/anhang/ monograph3.pdf. Access date: 10 July 2009.

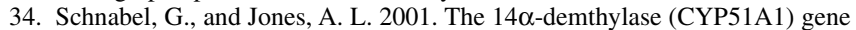
is overexpressed in Venturia inaequalis stains resistant to myclobutanil. Phytopathology 91:102-110.

35. Szkolnik, M., and Gilpatrick, J. D. 1969. Apparent resistance of Venturia inaequalis to dodine in New York apple orchards. Plant Dis. Rep. 53:861864.

36. Wicks, T. 1974. Tolerance of the apple scab fungus to benzimidazole fungicides. Plant Dis. Rep. 60:818-819.

37. Ypema, H. L., and Gold, R. E. 1999. Kresoxim-methyl: Modification of a naturally occurring compound to produce a new fungicide. Plant Dis. 83:419. 